УДК 556.55:551.332.56(571.15)

К МЕТОДИКЕ ОЦЕНКИ РАСХОДОВ ВОДЫ В ЧУЙСКО-КУРАЙСКОМ ЛЕДОВО-ПОДПРУДНОМ ОЗЕРЕ В СТАДИИ ДЕГРАДАЦИИ

${ }^{1}$ Поздняков А.В., ${ }^{1,2}$ Хон А.В.

${ }^{\prime}$ ФББУН «Институт мониторинга климатических и экологических систем» СО РАН (ИМКЭС СО РАН), Томск,

${ }^{2}$ ФАОУ ВО «Томский государственный университет», Томск, e-mail: synergeia.pol@gmail.com

Неоплейстоценовое Чуйско-Курайское ледниково-подпрудное озеро оставило следы в виде абразионно-аккумулятивных уступов на бортах Чуйской и Курайской межгорных впадин. Согласно опубликованным данным, в максимум наполнения до абсолютной отметки уровня 2100 м, при объеме 600 км$^{3}$, площадь акватории палеоозера составляла 2653 км². При спуске озера в интервале высот 1540-2100 м образовалось более 150 абразионных уступов различной высоты. Проведенный анализ изменения уровня озера свидетельствует, что опорожнение озера было неравномерным и не одномоментным, как полагается. Важное теоретическое и прикладное значение имеет определение расходов воды при спуске озера. Единственным источником информации для этого являются морфометрические характеристики абразионных уступов. Очевидно, что высота уступов, при известной соответствующей им площади поверхности озера, позволяет определить только объем истекающей воды. Для количественной оценки расходов воды необходимо определить продолжительность формирования уступов (соответственно, скорость понижения уровня) и расходов воды. С этой целью проведен анализ зависимости изменения высот абразионных уступов от абсолютной высоты понижавшегося уровня озера и определены их тренды. Установлено, что тренды исходных высотных рядов по двум профилям уступов для Курайской и Чуйской частей котловин имеют ясно выраженный характер сезонности: возрастающая величина понижения уровня чередуется с его уменьшающейся величиной. Видимо, причиной являлось изменение расходов воды в летние и зимние сезоны года. Расход воды в летние периоды в мини-

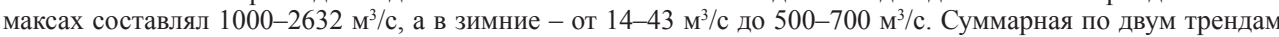
продолжительность спуска озера составляла 17 лет при общей величине понижения уровня озера на 373 м.

Ключевые слова: ледниково-подпрудное озеро, абразионные террасы, тренд высот уступов, расход воды

\title{
TO THE METHODOLOGY OF ESTIMATION OF WATER EXPENDITURES IN THE CHUISKO-KURAIS ICE-CONSTRUCTIVE LAKE IN THE STAGE OF DEGRADATION
}

\section{${ }^{1}$ Pozdnyakov A.V., ${ }^{1,2}$ Khon A.V.}

${ }^{1}$ Institute of Monitoring of Climatic and Ecological Systems of the Siberian Branch of the Russian Academy of Sciences (IMCES SB RAS), Tomsk;

${ }^{2}$ National Research Tomsk State University, Tomsk, e-mail: synergeia.pol@gmail.com

The Neo-Pleistocene Chuya Kurai glacial-pond lake left traces in the form of abrasion-accumulation ledges on the sides of the Chuya and Kurai intermontane depressions. According to the published data, the area of the Paleolake waters was $2653 \mathrm{~km} 2$ in maximum filling up to altitudes of $2100 \mathrm{~m}$ and the volume of $600 \mathrm{~km} 3$. When the lake descended in the interval of heights from 1540 to $2100 \mathrm{~m}$, more than 150 abrasion ledges of different heights were formed. The analysis of changes in the lake level indicated that the emptying of the lake was uneven and not instantaneous, as it is supposed. Important theoretical and applied importance has the definition of water consumption during the descent of the lake. The only source of information for this are the morphological characteristics of abrasion ledges. It is obvious that the height of the ledges, at known corresponding surface area of the lake, allows to determine only the volume of the flowing water. To quantify the water consumption is necessary to determine the duration of ledges formation (respectively, the speed of lowering of the level) and water flow. With this purpose, the analysis of the variation of the abrasion ledges heights from the absolute height of the lowering lake level was held and their trends were defined. It is established that the source elevation trends of series two profile ledges for Kurai and Chuya parts of the basins are clearly expressed seasonality: increasing the value of lowering the level alternates with its decreasing value. Apparently, the reason was the change of water consumption in the summer and winter seasons. Water consumption in the summer period minimaxed was $1000-2632 \mathrm{~m} 3 / \mathrm{s}$ and in winter from $14-43 \mathrm{~m} 3 / \mathrm{s}$ up to $500-700 \mathrm{~m} 3 / \mathrm{s}$. Total two trends in the duration of the lake descent was 17 years with a total dimension of lowering the lake level is at $373 \mathrm{~m}$.

Keywords: glacier-pond lake, abrasion terraces, trend of heights of ledges, water flow

Чуйско-Курайское ледово-подпрудное озеро образовалось на границе неоплейстоцена и голоцена в пределах Чуйской и Курайской межгорных котловин юго-восточной части Горного Алтая. Эта система котловин вытянута с северо-запада на юго-восток (крайние географические координаты $-49^{\circ} 42^{\prime}$ и $50^{\circ} 17^{\prime}$ с.ш. и $87^{\circ} 47^{\prime}$ и $89^{\circ} 14^{\prime}$ в.д.). Горное обрамление котловин включает Северо-Чуйский и Южно-Чуйский хребты с юга, Курайский хребет с севера и хребты Сайлюгем и Чихачева с востока и юго-востока. Абсолютные высоты днища Курайской котловины варьируют от 1480 м в центральной части до 1750 м по периферии. В Чуйской котловине этот диа- 
пазон составляет от 1700 до 2000-2150 м абс. высоты соответственно. Для горного обрамления Чуйской и Курайской котловин характерен типичный альпийский рельеф.

В формировании и деградации этого феномена отражается множество различных по генезису и динамике процессов, без преувеличения имеющих важное теоретическое, научно-познавательное и практическое значение.

Согласно опубликованным данным [1], в максимум наполнения до абсолютной отметки уровня 2100 м, при объеме 600 км $^{3}$, площадь акватории палеоозера составляла

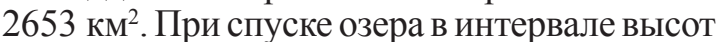
1540-2100 м образовалось более 150 абразионных уступов различной высоты, свидетельствующих, что опорожнение озера было неравномерным и не одномоментным, как полагают некоторые авторы [2-4].

Наибольший научный и теоретический интерес имеет определение расходов воды при спуске озера. Единственным источником информации для этого являются морфометрические характеристики абразионных уступов. Очевидно, что высота уступов, при известной соответствующей им площади поверхности озера, позволяет определить только объем истекающей воды. А чтобы определить расход Q воды, необходимо знать время, в течение которого происходило понижение уровня и формирование уступов. До сих пор расход воды из озера определяется на основе гидрофизически не обоснованных положений. В частности, утверждается [2, 3], что спуск озера был катастрофическим - сброс всего объема воды $\left(\mathrm{V}=600\right.$ км$\left.^{3}\right)$ Чуйско-Курайского озера произошел в течение нескольких часов.

В статье излагаются предварительные результаты анализа изменения относительных высот абразионных уступов, формировавшихся в процессе понижения уровня озера, и впервые предлагается методология количественной оценки расходной части $\mathrm{Q}$ баланса. В основу положены фактические материалы, полученные по результатам специализированных исследований по программам (грантам) РФФИ: № 01-05-65151 (a) - «Самоорганизация флювиогляциальных катастроф (на примере Горного Алтая)» (2001-2003 гг.) и № 05-05-64182 - «Формирование горно-долинных озерных бассейнов в Алтае-Саянской горной области вследствие неотектонических перекосов поверхности» (2005-2007 гг.), одной из главных целей которых являлось исследование закономерностей опорожнения Чуйско-Курайского ледово-подпрудного озера, происходившее на границах неоплейстоцена и голоцена; использованы материалы, полученные в 20052007 гг. по результатам нивелирования абразионных уступов и картографического отображения рельефа Курайской котловины.

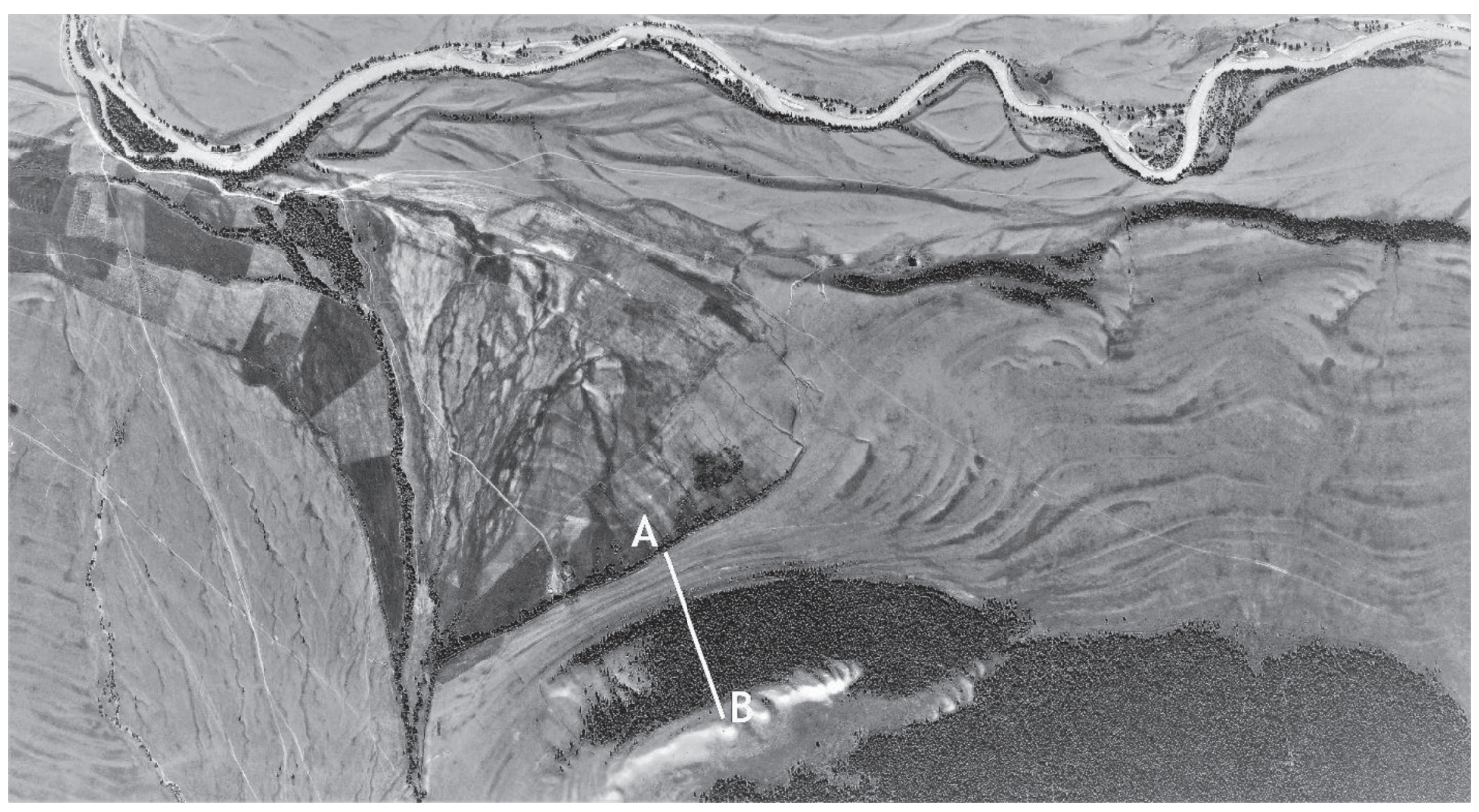

Рис. 1. Террасы на склонах Курайской котловины (абсолютная высота 1610-1750 м, скан Goоgle Earth) как прямое свидетельство существования Чуйско-Курайского ледово-подпрудного озера и как неоспоримое по форме и содержанию доказательство их абразионно-аккумулятивного генезиса. A-B-поперечный профиль через абразионные уступь 


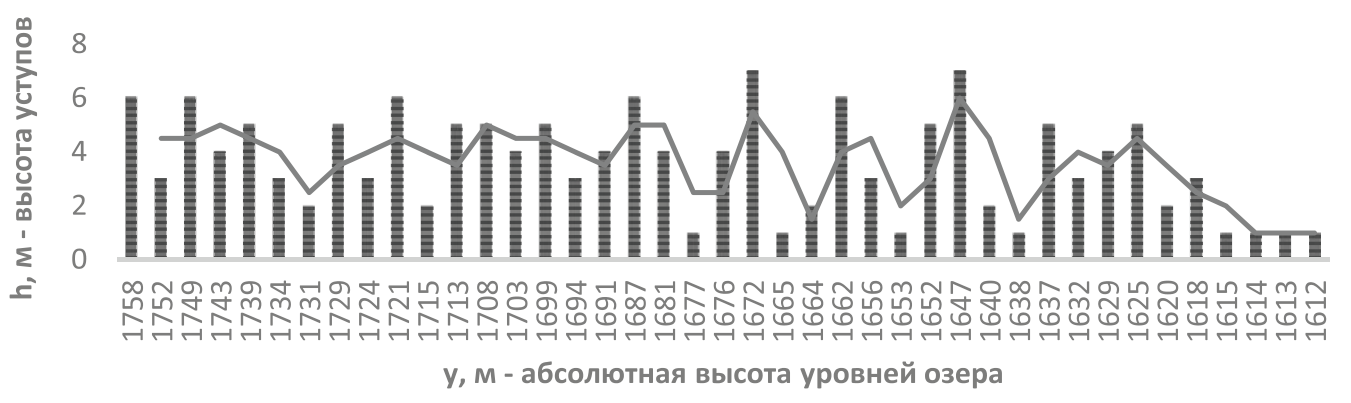

$A$

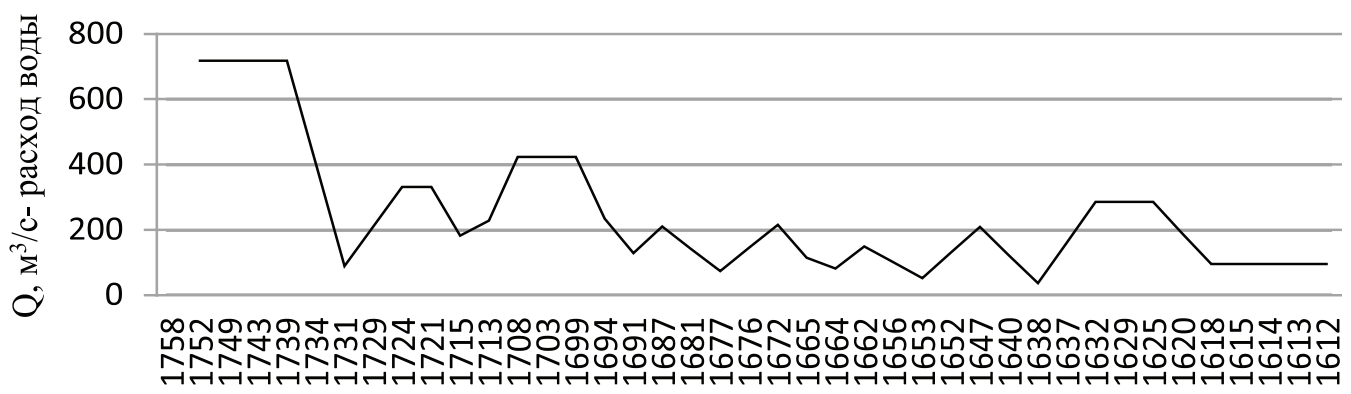

у, м - абсолютная высота уровней озера

Б

Рис. 2. Графики трендов. Изменения: $A$ - высоты $h(y)$ абразионных уступов; 5 - расходов $Q(y)$ воды. Курайская часть Чуйско-Курайского ледово-подпрудного озера

Закономерности изменения высот абразионных уступов и постановка задачи определения расхода воды. Абразионные уступы являются единственным из всех сохранившихся источником информации для определения $Q$ во время спуска озера, и потому сравнительный анализ распределения их высот в зависимости от абсолютной высоты стояния уровня озера имеет определяющее значение. Основной причиной изменения высоты $h(t)$ абразионных уступов является прерывистое или происходящее с замедлением понижение уровня $y(t)$ водного бассейна, являющегося функцией $Q(t)=\omega^{*} v$, где $\omega$ - площадь поперечного сечения каналов стока в плотине; $v$ - скорость течения воды в каналах. Существует еще одна причина формирования абразионных уступов, она обусловлена особенностями самоорганизационных процессов. Теоретически установлена возможность формирования террас в условиях медленного равномерного понижения уровня моря (или озера), как результат континуально-дискретного проявления внутренних самопроизвольно образующихся противоречий в процессах абразионно-аккумулятивной деятельности.
Однако для их развития необходимы идеальные сочетания условий по длительности времени, постоянству морфометрических характеристик исходной поверхности, показателей абразионной устойчивости пород и пр. Поэтому они в данном процессе не учитываются.

Объем $V$ истекающей из озера воды и площадь $S$ его водной поверхности во времени являются функциями понижения уровня $\Delta y(t)=Q$. Согласно данным [1], изменение высоты абразионных уступов $(\Delta h=\Delta y)$ Чуйско-Курайского озера происходит стохастически, основной причиной, очевидно, являлось непостоянство площади поперечного сечения $\omega(t)$ каналов стока в ледовой плотине и расходов $Q(\omega)$ воды. В условиях кратковременности спуска озера выявить закономерности в случайных изменениях $\omega(t)$ и, соответственно, высоты абразионных уступов, не представляется возможным. Однако когда количество абразионных уступов, как в данном случае, велико (более 150), то логично считать, что понижение уровня озера было длительным, и тогда можно полагать, что на стохастичность распределения высот абразионных 
уступов накладывались периодически действовавшие упорядоченные процессы. В таком случае в стохастическом распределении высот абразионных уступов должны наблюдаться закономерные изменения их высот. И тогда появляется возможность количественной оценки $V(y), S(y), \omega(t)$ и связанных с ними изменений расхода $Q(\omega)$ воды.

Сезонные тренды высот абразионных уступов и кластеры уровней озера. Для проверки гипотезы проведен анализ распределения высот $h(y)$ уступов в зависимости от абсолютной высоты $y$ уровня озера. С использованием GPS и глазомерных методов измерения в августе 2005 г. был построен поперечный профиль лестницы уступов на левом борту Курайской части котловины в границах абсолютных высот 1612-1758 м, где абразионно-аккумулятивный террасовый комплекс морфологически выражен наиболее контрастно (рис. 1). В результате были установлены морфометрически четко выраженные 43 абразионно-аккумулятивных уступа различной высоты (рис. 2, А), по которым построен тренд (рис. 2, Б) их распределения. Он, как видно, характеризуется периодичностью чередования кластеров высот $\Delta h$ абразионных уступов и уровней понижения озера (поскольку $\Delta h=\Delta y$ ), характерной для так называемых сезонных трендов.

Такой же сезонный тренд установлен по независимым результатам измерения высот абразионных уступов в Чуйской части озера [1], в пределах абсолютных высот 1802 - 1980 м. Он составлен по измерениям высот 34 абразионных уступов (к сожалению, в статье не указывается привязка точек измерения к координатам; главным же достоинством этих результатов, по утверждениям авторов, является высокая точность измерений высоты, составлявшая 0,5 м). И в этом случае тренд имеет вид ясно выраженной сезонности (рис. 3, А): кластеры высоких уступов (4-7 м) чередуются с кластерами высот 1-3 м. Таким образом, тренды высот уступов, построенные на основе независимых исходных данных и для разных участков Чуйско-Курайской котловины, характеризуют закономерность понижения уровня ледово-подпрудного озера.

Это интереснейшее обстоятельство свидетельствует о ритмичности протекавшего процесса, наиболее вероятной причиной которого были сезонные (зима - лето) изменения водопропускной способности $(Q(\omega)$ каналов стока в ледовой плотине. Видимо, оно было связано с физическим состоянием ледовой плотины, что определялось погодными условиями в зимнее и летнее время: кластеры, соответствующие минимальным значениям высот уступов, характеризуют зимний режим спуска озера, а максимальным - летним. С наступлением сезона преобладающих положительных температур воздуха (на переходах весна - лето - осень) понижение уровня существенно увеличивалось, а в зимнее время оно хотя и продолжалось, но было меньше.

Анализ трендов расхода $Q$ воды и закономерности спуска озера. Учитывая выявленные закономерности сезонных трендов, для каждого кластера, соответствующего абсолютным высотам уровня озера, по номограмме [1] определены площадь $S(h)$, км$^{2}$ поверхности озера; объем $V(h)$, км ${ }^{3}$ воды в слое толщиной $h$, равной соответствующей высоте абразионных уступов. Для определения расхода $Q(h)$ воды при понижении уровня озера на $h$ продолжительность сезонов принята близкой современной, составлявшей для кластеров зимних и летних уровней 7 и 5 месяцев соответственно. По результатам анализа составлены сезонные тренды расходов воды (рис. 2, Б и 3, Б).

Как следует из представленного фактического материала, опорожнение озеpa было неравномерным. Пропускная способность $\omega(\mathrm{t})$ плотины менялась не только от физических и, так сказать, конструктивных ее свойств, но еще и от климатических характеристик на границах перехода «зима - лето». Можно полагать, что в палеогеографическое зимнее время спуск озера мог останавливаться полностью; даже в настоящее время, при потеплении климата и ускоряющемся таянии ледников, расход воды в р. Чуя, по замерам у с. Чаган-Узун, в зимние месяцы сокращается до 5-6 м³/с, при максимальных летних расходах до $49 \mathrm{~m}^{3} / \mathrm{c}$ [5]. В то же время, судя по трендам Q(h) (рис. 2, 3), понижение уровня озера в зимнее время могло сопровождаться паводками, следы которых наблюдаются в морфолитогенетических особенностях строения террасового комплекса в нижнем бьефе [6].

\section{Результаты исследования и их обсуждение}

На основе профилирования лестниц абразионных уступов на склонах Чуйской и Курайской частях котловин установлено определенным образом упорядоченное распределение их относительных высот 
по абсолютной высоте стояния уровня ледово-подпрудного озера. Тренды профилей абразионных лестниц, формировавшихся при понижении уровня озера на 125 м за 9 лет в Чуйской части существовавшего водного бассейна и на 148 м за 8 лет в Курайской, выявляют периодическую упорядоченность по высоте их уступов. Известно, что устойчивость тренда определяется его протяженностью (в данном случае количественно охарактеризованная общая величина понижения уровня озера составляет 273 м); продолжительностью (по времени общая продолжительность спуска озера и абразионно-аккумулятивных процессов составляла 17 лет); числом количественно оцененных зависимых переменных (72 абразионных уступа). Таким образом, можно полагать, что установленная ясно выраженная упорядоченность распределения высот абра- зионных уступов по абсолютной высоте стояния уровня озерного бассейна характеризует не что иное, как сезонные изменения расходов воды.

Анализ изменения уровня озера, проведенный по оставленным им следам абразионно-аккумулятивной деятельности, свидетельствует о континуально-дискретном его понижении. Тренды профиля высот $\mathrm{h}(\mathrm{y})$ абразионных уступов и определенных по ним расходов $Q(h)$ для теплого и зимнего периодов года в пределах Чуйской части водного бассейна существенно различаются. Расходы воды в летний период, когда уровень воды снижался на 12-19 м, в пределах минимакса составляли $Q=1000-2632 \mathrm{~m}^{3} / \mathrm{c}$. Зимние расходы воды в максимуме, при понижении уровня на 6-7 м, достигали $Q(h)=500-700 \mathrm{~m}^{3} / \mathrm{c}$, а в минимуме $-Q=14-43 \mathrm{~m}^{3} / \mathrm{c}$ (уровень озера понижался на 1-3 м).

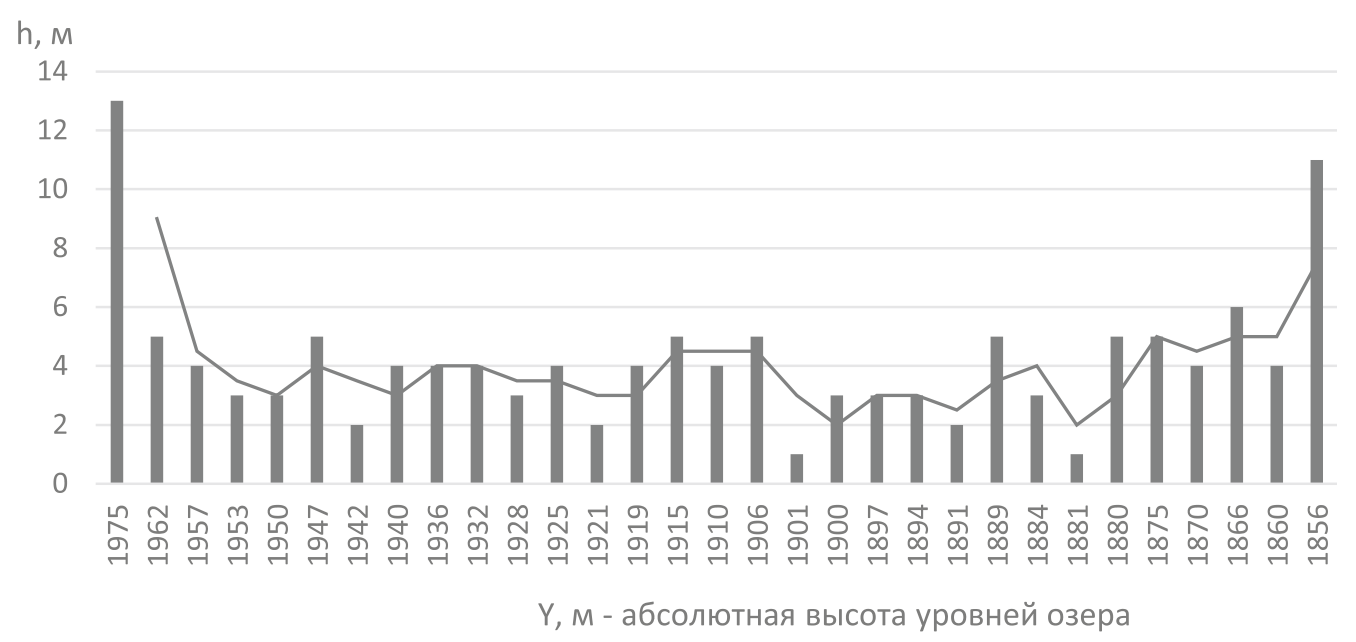

$A$

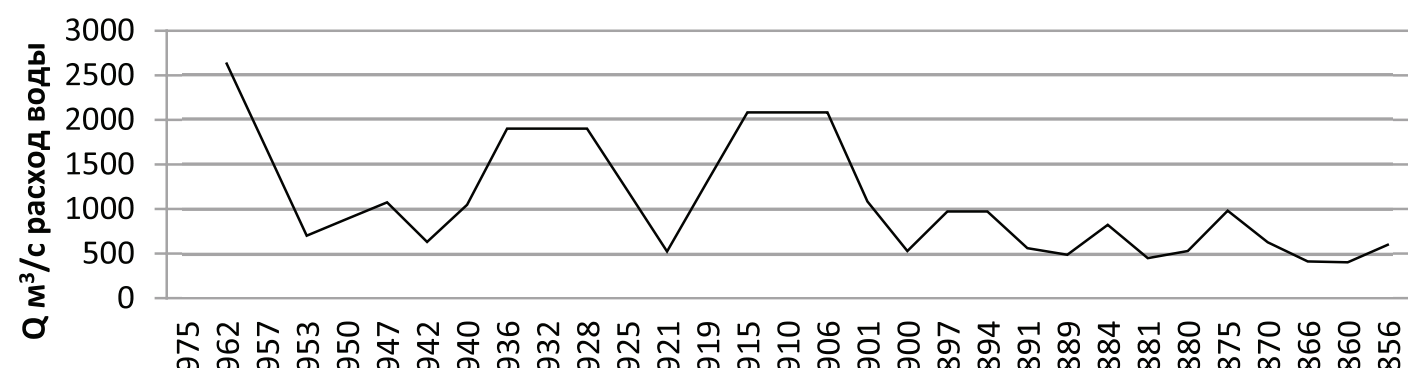

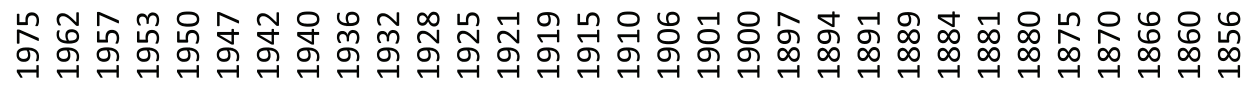

у м - абсолютная высота уровней озера

Рис. 3. Сезонные тренды изменения: (А) высот абразионных уступов и (Б) расходов воды (составлен по материалам [1]) 
Аналогичными закономерностями характеризуется континуально-дискретный процесс понижения уровня озера и расходов воды в Курайской части ледово-подпрудного озера. Здесь максимальные летние расходы воды составляли $Q=284-717,3 \mathrm{~m}^{3} / \mathrm{c}$, а зимние $-95 \mathrm{~m}^{3} / \mathrm{c}$ (превышали современный летний расход в р. Чуя в два раза). Минимальный расход составлял менее $14 \mathrm{~m}^{3} / \mathrm{c}$.

Как следует из анализа фактического материала, опорожнение озера было неравномерным, и тем более не одномоментным. Результаты исследования опровергают утверждения о том, что лестница абразионных уступов является «...не свидетельствами долговременных береговых линий, а следами боковой водной эрозии при спуске палеоозера после прорыва ледниковой плотины〉» [7, с. 76].

Конечно же, полученные количественные характеристики расходов воды из озера не претендуют на абсолютную точность. Тем не менее можно утверждать, что они с достаточной объективностью отражают сравнительный порядок величин, позволяющий увидеть близкий к реальному ход событий. Результаты проведенного анализа подтверждают ранее высказанные нами суждения [8, 9] о невозможности одновременного развития процессов абразионно-аккумулятивной переработки склонов котловины и катастрофического спуска озера, сопровождавшегося формированием водного потока со скоростью течения, превышавшей $10 \mathrm{M} / \mathrm{c}$, и расходом воды $Q>4,5=10$ млн м³ 3 .

Учитывая научно-теоретическую и прикладную значимость проблемы формирования ледово-подпрудных плотин и их разрушения с образованием катастрофических явлений преобразования экосистем, в дальнейшем необходимо проведение высокоточного нивелирования абразионных уступов в наиболее характерных участках ЧуйскоКурайской котловины.

\section{Список литературы}

1. Окишев П.А. Реконструкции «флювиальных катастроф» в горах южной Сибири и их параметры / П.А. Окишев, П.С. Бородавко // Вестник Томского государственного университета. - 2001. - № 274. - С. 3-12.

2. Инишев Н.Г. Первая компьютерная модель течений в межгорной котловине при сбросе ледниково-подпрудного озера (на примере Курайской котловины, Горный Алтай)/ Н.Г. Инишев, А.Н. Рудой, В.А. Земцов, Д.А. Вершинин // Докл. Акад. наук. - 2015. - Т. 461, № 2. - С. 220-222.

3. Jurgen Herget. Recostructionof Pleistocene icedammed lake outburst floods in the mountains, Siberia // The geological society of America. - Boulder, Colorado, USA, 2005. - $118 \mathrm{p}$.

4. Baker V.R. Extreme Events and Catastrophism in Geomorphology: Some Historical and Philosophical Perspectives // Gradualism vs Catastrophism in Landscape Evolution. Extended abstractsof International conference. Barnaul: Publishing House of Altai State University, 2015. - P. 9-12.

5. Ресурсы поверхностных вод СССР. Основные гидрологические характеристики. В 20 т. - Л.: Гидрометеоиздат, 1969. - Т. 15, вып.1, ч. 1. - 316 с.

6. Pozdnyakov A.V., Borodavko P.S. Algorithm of natural cataclysm in SE Altai at the Pleistocene / Holocene boundary and its effects on geosystems dynamics// Gradualism vs Catastrophism in Landscape Evolution. Extended abstractsof International conference. - Barnaul: Publishing House of Altai State University, 2015. - Р. 55-60.

7. Зольников И.Д. Гляциальные суперпаводки на территории Горного Алтая в четвертичном периоде: условия формирования и геологические признаки / И.Д. Зольников, Е.В. Деев // Криосфера Земли. - 2013. T. XVII, № 4. - С. 74-82.

8. Поздняков А.В., Тимофеев Д.А. Происхождение грядового рельефа Курайской котловины Горного Алтая // Геоморфология. - 2007. - № 2. - С. 78-89.

9. Поздняков А.В., Хон А.В. О генезисе «гигантской ряби» в Курайской котловине Горного Алтая // Вестник Томского государственного университета. - 2001. T. 274. - C. 24-33.

\section{References}

1. Okishev P.A. Rekonstrukcii «fljuvialnyh katastrof» V gorah juzhnoj Sibiri i ih parametry / P.A. Okishev, P.S. Borodavko// Vestnik Tomskogo gosudarstvennogo universiteta. 2001. no. 274. pp. 3-12.

2. Inishev N.G. Pervaja kompjuternaja model techenij v mezhgornoj kotlovine pri sbrose lednikovo-podprudnogo ozera (na primere Kurajskoj kotloviny, Gornyj Altaj) / N.G. Inishev, A.N. Rudoj, V.A. Zemcov, D.A. Vershinin // Dokl. Akad. nauk. 2015. T. 461, no. 2. pp. 220-222.

3. Jurgen Herget. Recostructionof Pleistocene icedammed lake outburst floods in the mountains, Siberia // The geological society of America. Boulder, Colorado, USA, 2005. 118 p.

4. Baker V.R. Extreme Events and Catastrophism in Geomorphology: Some Historical and Philosophical Perspectives // Gradualism vs Catastrophism in Landscape Evolution. Extended abstractsof International conference. Barnaul: Publishing House of Altai State University, 2015. pp. 9-12.

5. Resursy poverhnostnyh vod SSSR. Osnovnye gidrologicheskie harakteristiki. V 20 t. L.: Gidrometeoizdat, 1969. T. 15, vyp.1, ch. $1.316 \mathrm{p}$.

6. Pozdnyakov A.V., Borodavko P.S. Algorithm of natural cataclysm in SE Altai at the Pleistocene / Holocene boundary and its effects on geosystems dynamics // Gradualism vs Catastrophism in Landscape Evolution. Extended abstractsof International conference. Barnaul: Publishing House of Altai State University, 2015. pp. 55-60.

7. Zolnikov I.D. Gljacialnye superpavodki na territorii Gornogo Altaja v chetvertichnom periode: uslovija formirovanija i geologicheskie priznaki / I.D. Zolnikov, E.V. Deev // Kriosfera Zemli. 2013. T. XVII, no. 4. pp. 74-82.

8. Pozdnjakov A.V., Timofeev D.A. Proishozhdenie grjadovogo relefa Kurajskoj kotloviny Gornogo Altaja // Geomorfologija. 2007. no. 2. pp. 78-89.

9. Pozdnjakov A.V., Hon A.V. O genezise «gigantskoj rjabi» v Kurajskoj kotlovine Gornogo Altaja // Vestnik Tomskogo gosudarstvennogo universiteta. 2001. T. 274. pp. 24-33. 